\title{
The New Deep Web Drug Market Place (And the role of Bitcoin as a Currency for Drugs)
}

\author{
SURYA IYER ${ }^{1}$, G. RAJA RAJESWARI ${ }^{2}$, ARUNA R ${ }^{3}$, BALAJI JAYAKRISHNAN ${ }^{4}$ \\ VELLORE INSTITUTE OF TECHNOLOGY, CHENNAI CAMPUS. \\ ${ }^{1}$ Email: surya.iyer2016@vitstudent.ac.in \\ 2Email: rajarajeswari.g@vit.ac.in \\ ${ }^{3}$ Email: aruna.r@vit.ac.in, \\ ${ }^{4}$ Email: balaji.jayakrishnan@vit.ac.in
}

\begin{abstract}
Drugs are a true menace to our society today. "Drug use on the rise" is an increasingly common headline in newspapers and it is well-known that this is the case. With the topic of drugs becoming more and more common in popular media, youngsters are especially influenced to try drugs. This is not a new problem, as such, and has been a relevant issue in modern society. Coupled with this, the internet plays a huge role in spreading information about emerging drugs (such as synthetic and 'designer' drugs). [Silk Road, Wikipedia] This paper aims to understand the role of the internet's Deep Web [Cox and Joseph, 2015) and Bitcoin (and other Crypto currencies) in dealing drugs online.
\end{abstract}

Keywords: Bitcoin; Silk Road; Crypto Currencies; Deep Web Market Places; Silk Route; E- Commerce; Garlicoin.

JEL Classification: C1, L2 


\title{
The New Deep Web Drug Market Place (And the role of Bitcoin as a Currency for Drugs)
}

\author{
SURYA IYER ${ }^{1}$, G. RAJA RAJESWARI ${ }^{2}$, ARUNA R ${ }^{3}$, BALAJI JAYAKRISHNAN ${ }^{4}$ \\ VELLORE INSTITUTE OF TECHNOLOGY, CHENNAI CAMPUS. \\ ${ }^{1}$ Email: surya.iyer2016@vitstudent.ac.in \\ 2Email: rajarajeswari.g@vit.ac.in \\ ${ }^{3}$ Email: aruna.r@vit.ac.in, \\ ${ }^{4}$ Email: balaji.jayakrishnan@vit.ac.in
}

\begin{abstract}
RESUMEN
Las drogas son una verdadera amenaza para nuestra sociedad actual. "Aumenta el consumo de drogas" es un titular cada vez más habitual en los periódicos y es bien sabido que así es. Con el tema de las drogas cada vez más presente en los medios de comunicación populares, los jóvenes se ven especialmente influenciados a probar las drogas. Este no es un problema nuevo, como tal, y ha sido un tema relevante en la sociedad moderna. Además, Internet desempeña un papel muy importante en la difusión de información sobre drogas emergentes (como las drogas sintéticas y de diseño). [Silk Road, Wikipedia] Este artículo pretende comprender el papel de la Deep Web de internet [Cox y Joseph, 2015) y de Bitcoin (y otras criptomonedas) en el tráfico de drogas online.
\end{abstract}

Palabras clave: Bitcoin; Silk Road; Criptomonedas; Mercados de la Web Profunda; Silk Route; Comercio Electrónico; Garlicoin.

Clasificación JEL: C1, L2 


\section{Introduction}

\subsection{Silk Road}

It is an online marketplace (a black market) for buying \& selling drugs. It was the first dark net market [NBC New York Associated Press 2011 4] and it was used primary to peddle banned drugs. As part of the black net, it was working as peak secreted provision, making it so that users would be able to look through it secretly and securely without possible traffic checking. In August 2010, development on the site started, which led to it being launched six months later in February 2011. [Foxton and Willard, 2013 5] The website's name is the namesake of the famous Silk Road or Silk Route, which was a trade route connecting India, Europe, China and other countries throughout Asia and Europe. It was popularized during the Han Dynasty (206 BC - 220 AD) in China. [Jeffries and Adrianne, 2013 6]

Silk Road was operated by an anonymous individual (later revealed to be Ross William Ulbricht) who went by the pseudonym "Dread Pirate Roberts". Helped by two other people, viz. Variety Jones and Smedley [Ross William Ulbricht 2014 7], Silk Road flourished into a well-rounded business, and generated huge amounts of internet traffic. When the location was known to everyone, US Senator Charles Schumer requested the Federal law Enforcement Officers to lock it, including the Drug Enforcement Administration and Division of Justice. (Roberts 2013 8)

During May 2013, the Silk Road has been has been down casted for a short duration of time by a continuous DDOS attack. (Greenberg and Andy, 2013 9) Followed by this, during 23rd June 2013, came to know that DEA detained 11.02 Bitcoins, which values a total of $\$ 814$, where the media alleged was the outcome of Silk Road honeypot sting. (Weiser and Benjamin, 2015 10)

During October 2013, the Federal Bureau of Investigation (FBI) closed the website (Andres Baravalle, Mauro Sanchez Lopez and Sin Wee Lee, 2016 11) and detained Ross Ulbricht under the charges of being the site's pseudonymous founder "Dread Pirate Roberts". (Fernando Caudevilla, 2016 12) Again on 6th November 2013, Silk Road came to online which was controlled by the former administrators of Silk Road. (Caudevilla, F., Ventura, M., Indave Ruiz, B. I. and Fornís, I 2013 13) This was also closed down and the suspected administrator was arrested on 6th November 2014 as a part of the so-called "Operation Onymous". Ulbricht was sentenced with eight charges which related to Silk Road in the US Federal Court in Manhattan and was punished to be in prison without any possibility of parole. (Johnson, L. A., Johnson, R. L. and Portier, R. B 2013 14)

The Silk Road phenomenon exposed the dark web's capability to be used as a black market. With a majority of the internet being hidden behind chains of onion links, being hidden away from the world serves to the benefit of sites that follow the spirit of Silk Road. [Van Hout, M. C. and Bingham, T 2013 15]

\section{Alpha bay: The Spiritual Successor to Silk Road}

The shutdown of Silk Road left the top spot empty in the dark net. Alpha Bay was the one to seize this opportunity. It became the next big thing after Silk Road and is considered as one of the largest online dark net markets. It was launched in September 2014 and gained 14,000 new users within the first 90 days. By October 2015, the site had over 200,000 users and by mid-2017, it crossed 400,000 users. A new feature that attracted users was that along with Bitcoin, Alpha Bay also supported Monroe which is more anonymous.

Alpha Bay made the news many times over the years when it started selling stolen Uber accounts and hacked the London-based telecommunication company TalkTalk. Alpha Bay continued to grow in size and by July 2017, it was ten times the size of Silk Road and facilitated around $\$ 700,000$ transactions every day. The seizure of Alpha Bay was all over the news and made it to the headlines. It was done under Operation Bayonet which was a multinational law enforcement operation aimed to close Alpha Bay, Hansa and several other dark net markets. The operation started in early May 2017 and culminated by end of July. 
The New Silk Road and Deep Web Marketplaces

Deep web marketplaces (DWMs) are closed-access forums and sites on the deep/dark web that conduct a majority of their transactions in crypto currencies. Earlier thought to be a limited phenomenon [Foley, S., Karlsen, J. R. and Putninš, T. J 2019 16], they have grown in importance and are now the economic backbone of the deep web. DWMs are set up in a way that allows communication and information exchange between the interested parties, which is one of the many reasons why they have expanded in the deep web.

As with the other trade goods, illicit medicines have been offered online since the conception of the deep web. However, till recently, their unlawful standing has created this business very tough in apply. Surface web (which is what most people access) market places offer no guarantees about the quality and delivery of illicit drugs. Payment and shipping permit the vendee to be physically known and there's no risk of lodging a criticism. Even still, tiny closed-access websites and forums have invariably existed wherever choose people should buy illicit medicine by invitation; their impact, however, has been restricted.

To fully understand the growth of the phenomenon of e-commerce in illicit substances, a full history has been provided below.

From the mid-90s to 2003, a small selection of hallucinogenic substances was offered online as "research chemicals". In general, they were phenethylamine and tryptamine derivatives, returning from discreet websites providing high-purity merchandise. A vast majority of customers were so-called "psychonauts", a portmanteau of psychoactive drugs and astronaut. They were individuals who had an interest in psychoactive drugs. The growth of such sites and forums didn't attract the eye of the media and lay under the radar. However, in July 2004, the US Drug social control Administration shut down most of those websites.

The phenomenon of selling drugs online saw a renaissance around 2007 in the form of "legal highs". To attract consumers, eye-catching websites and special promotion offers were used, such as BOGO (buy one get one free) and others. These websites offered a wide variety of drugs (synthetic cannabinoids, cathinone derivatives, pyrovalerones, NBOMe series, methoxetamine, etc.) marketed as herbal blends, incense, fertilisers, and so on. The purpose of this market was to sell non-controlled substances. The substances in question were not tested for effects on animals; very little, if at all, was known about the psychoactive effects of these drugs. In many cases, product samples contained a mixture of different substances and, sometimes, products with identical labels contained different active substances. [Lester Grinspoon, James 2019 17] There was high availability of these substances, some of which have been shown to have much potential for harm. [Miller P. G., Sønderlund A. L 2019 18]

After the events of the Silk Road and "legal high" marketing, DWMs turned the online drug transaction industry on its head, making it so that relations between buyers and sellers were based on professionalism and trust. Feedback and resolution models [Rooney, K., and A. Levy 2018 19] helped to keep the system in check and popular with their users. The discussion pages and forums of these websites were appropriately provided with user feedback, "trip feedback", suggestions, and transaction reviews. Some of these markets sold only psychoactive substances, and were firm believers of reducing harm caused by drugs. These websites had guides and other information about how drugs should be consumed, what effects they would have, what preparation is needed, et cetera. Famously, some DWMs have put up stolen credit cards, weapons, and some counterfeit goods, along with their usual drug offerings. However, unlike the rest of the deep web, offering child pornography, hit contracts, traffic of persons or human organs, et cetera are strictly forbidden.

DWMs may also help to reduce damage to their consumers. The structure of DWMs permits the creation of virtual communities that share data, information and experiences. For several people, it's not a matter merely of 'buying drugs', however a matter of happiness to a community that shares similar interests. The implications of those aspects for hindrance merit careful analysis. Feedback from alternative users, posts in forums and management by web site directors enable users to be 
comparatively well sophisticated concerning the standard of product. Several vendors state that their products are 'lab-tested' and supply data concerning purity. Users will leave their opinions concerning the standard of product and experiences with vendors. Several vendors communicate directly with users in forums, announce once a replacement batch of a substance is on the market, give and share recommendation concerning safer use and brazenly discuss quality, purity, adulterants and advertisements. This method is imperfect; it offers users additional reliable data than that provided within the ancient drug dealing system. All things considered, DWMs are a welcome alternative to street dealers.

\section{Crypto Currencies and Their Role in the Deep Web}

Crypto currencies have been considered as one of the largest unfettered markets in the world. Nearly one-quarter of Bitcoin users are indulged in illegal activities. It was estimated that $\$ 76$ billion Bitcoin illegal transactions has been occurred per annum (46 per cent of Bitcoin transactions). Recently, Bit Coin has fallen from public grace, with more opaque crypto currencies such as Garlicoin leading the charge (and the market). With this decline in public attention, the criminal share has gone down considerably. However, crypto currencies are reworking the black markets by enabling "black" e-commerce. [Rooney, K., and A. Levy 2018 20]

Crypto currencies have seen a rise in popularity and price, along with being worked into the global economy. As of November 2019, there are 2,824 crypto currencies. [Rooney, K., and A. Levy 2018 21] Bitcoin accounts for almost half of the market cap of these, which is to be expected, it was considered as the most famous crypto currency since the beginning of crypto currencies.

Accompanying the crypto currency boom, "crypto funds" emerged as hedge funds that only invest in crypto currencies. As of 2018, over 300 of these hedge funds have surfaced, garnering over $\$ 10$ billion in management assets. [swensen 2018 22]

Perhaps the biggest challenge to regulatory authorities is the fact that crypto currencies have been growing rapidly and that they provide their users with anonymity. These challenges are growing concerns for the U.S. SEC (Securities and Exchange Commission). In 2017, the SEC rejected the application for a \$100 million crypto currency ETF (exchange-traded fund) and in 2018 it rejected several others. Following up on concerns of regulation, the Chinese government took firm action, banning Chinese residents from trading in crypto currencies and ICOs (Initial Coin Offerings).

Among others, a public voice against crypto currencies belonged to Mark Carney from Bank of England. Crypto currencies' benefits have been consistently proven to work against them, with evidence of crypto currencies funding illegal trade of drugs, pornography, et cetera, and even terrorism. The biggest concern is that crypto currencies can completely loophole capital regulations, with a stress on being decentralized and having no government involvement.

As evidenced by the famous website Silk Road (section 1.), Bitcoin and other crypto currencies has eased the development of Deep Web Marketplaces (section 2.). The current FBI confiscation of $\$ 4$ million worth of Bitcoin from the Silk Road clearly depicts the growth of the money and how it is evading the federal controllers which is residing in crypto currencies.

\section{Conclusion}

This paper highlights the role of Silk Road as the progenitor of many Deep Web Marketplaces (DWMs). The sale of illicit drugs as a trend was also appropriately documented, with the rise of "legal highs" and synthetic and designer drugs. Finally, the role of Bitcoin and other crypto currencies has been discussed in detail, and it is quite clear that the anonymous nature of crypto currencies can cause issues to regulatory and centralized authorities.

DWMs have seen a rise in popularity and are now common on the dark web. To accompany this claim, several onion links have been added to the references and links section. These onion links are only accessible through Tor and must be browsed at the user's discretion. Proper safety procedures must be followed while accessing the dark web - this has been made very clear through the rampant rise of hackers on the dark web. 
As a whole, the phenomenon of selling drugs online is as old as the internet. However, with the rise of DWMs and crypto currencies, many challenges have been posed to regulatory authorities. It is now upon them to stop the spread of illicit substances

\section{References}

1. Justin Norrie, Asher Moses, 2011 Drugs bought with virtual cash The Sydney Morning Herald. Fairfax Media.

2. Silk Road, Wikipedia: https://en.wikipedia.org/wiki/Silk_Road.

3. Cox and Joseph, 2015 These Are the Two Forgotten Architects of Silk Road.

4. Schumer Pushes to Shut Down Online Drug Marketplace 2011 NBC New York Associated Press.

5. Foxton and Willard, 2013 The online drug marketplace Silk Road is collapsing - did hackers, government or Bitcoin kill it? The Telegraph.

6. Jeffries and Adrianne, 2013 Drug Enforcement Administration seizes 11 Bitcoins from alleged Silk Road dealer, The Verge.

7. Sealed Complaint 13 MAG 2328: United States of America v. Ross William Ulbricht 2014, 6.

8. Ars Technica, 2013 How the feds took down the Dread Pirate Roberts.

9. Greenberg and Andy, 2013 Silk Road 2.0' Launches, Promising A Resurrected Black Market for The Dark Web Forbes.

10.Weiser and Benjamin, 2015 Ross Ulbricht, Creator of Silk Road Website, Is Sentenced to Life in Prison The New York Times.

11.Andres Baravalle, Mauro Sanchez Lopez and Sin Wee Lee, 2016 IEEE 16th International Conference on Data Mining Workshops (ICDMW) Mining the Dark Web: Drugs and Fake Ids.

12.Fernando Caudevilla, gwern.net The emergence of deep web marketplaces: a health perspective.

13.Caudevilla, F., Ventura, M., Indave Ruiz, B. I. and Fornís, I 2013 Presence and composition of cathinone derivatives in drug taken from a drug test service in Spain Human Psychopharmacology: Clinical and Experimental 341-344.

14.Johnson, L. A., Johnson, R. L. and Portier, R. B 2013 Current "legal highs" Journal of Emergency Medicine 1108-1115.

15.Van Hout, M. C. and Bingham, T 2013 Silk Road The virtual drug marketplace: a single case study of user experiences International Journal of Drug Policy 385-391.

16.Foley, S., Karlsen, J. R. and Putninš̌, T. J 2019 Sex, Drugs, and Bitcoin: How Much Illegal Activity Is Financed through Cryptocurrencies? The Review of Financial Studies 32(5) 1798-1853.

17.Lester Grinspoon, James Band Bakalar Psychedelic Drugs Reconsidered.

18. Miller P. G., Sønderlund A. L Using the internet to research hidden populations of illicit drug users: a review.

19.White Paper: The Deep Web: Surfacing Hidden Value.

20.Casefile: True Crime Podcast. 11th February 2018.

21.Rooney, K., and A. Levy 2018 The most influential endowment manager just jumped into crypto with bets ontwo Silicon Valley funds.cnbc.com,

22.https://www.cnbc.com/2018/10/05/yale-investment-chief-david-swensen-jumps-into-cryptowith-bets-on-two-silicon-valley-funds.html

23. https://www.investing.com/crypto/currencies 